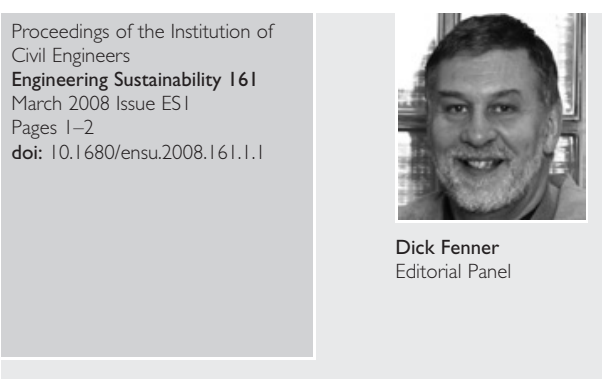

\title{
Editorial: Can sustainability count?
}

\section{R. A. Fenner PhD, CEng, MICE, FCIWEM}

This issue of the journal is Part Two of a special issue devoted to assessment frameworks, indicators and metrics. It contains nine full papers and this represents the biggest single issue of the journal since it was launched in March 2003. It is very pleasing to see that over the last five years Engineering Sustainability has fully established itself as a premier outlet for the publication of this material. Furthermore, the extent of papers on this topic reflects the vital importance of developing methods to monitor and assess the progress that is being made towards sustainability in engineering projects.

The need for robust assessment frameworks is an essential component of our ability to engineer sustainability. But there are pitfalls and dangers of inappropriate methodologies being misapplied in the wrong circumstances, with little regard for understanding the wider context of the problem. It was Lord Kelvin who noted the following in 1883

I often say that when you can measure what you are speaking about, and express it in numbers, you know something about it; but when you cannot measure it, when you cannot express it in numbers, your knowledge is of a meagre and unsatisfactory kind.

This reflects the classical reductionist approach to problem solving: deconstruct the problem into component parts and analyse each from a quantitative perspective. But as Elghali, Clift, Begg and McClaren observe in the furst paper of this issue, this may be appropriate for complicated systems (i.e. those rich in detail but which do not require scrutiny from multiple perspectives), but is a less appropriate approach when dealing with levels of complexity associated with sustainability. As Paul Jowitt observed in the Editorial to Part One of this special issue (June 2007): 'Finite elements are complicated. Sustainable development is complex ... (and) .. difficult!'.

To counter Kelvin's view I favour a quote from Albert Einstein, who said

Not everything that can be counted counts, and not everything that counts can be counted.

Together, Einstein and Kelvin sum up the fundamental dilemma for engineering sustainability. That is the translation from a problem needing to be defined by complexity science to a solution that must be delivered by Newtonian science.
These concepts, emphasising the qualitative as well as the quantitative, are implicit in the second paper presented here, by Hurley, Ashley and Mounce, who also recognise the problem of applying reductionist thinking to complex problems. They point to emergent properties not being captured by a criteria-indicator approach to sustainable development assessment; the need for a deeper understanding of complex social preferences; the current narrow emphasis on climate change and carbon footprints, rather than a broader sustainability picture; the need for engineers to seek 'non-build' solutions; and the iterative nature of assessment procedures and making decisions within appropriate boundaries.

Ciria $^{2}$ suggested that indicators should be relevant, representative, repeatable, responsive to change and reasonably simple to interpret. Ciria also described effective targets as being smart: specific to each indicator, measurable, achievable but challenging, realistic and time-bound. But others have identified a range of problems with using indicators. Values may have to be assessed subjectively by experts. ${ }^{3}$ It is tempting to choose indicators that are easy to measure, and indicators may oversimplify (or inadequately represent) complex processes. ${ }^{4}$ Relative weightings of indicators and the methods used for combining them may also create bias. ${ }^{5}$ Considerable care and caution must therefore be exercised in applying any of the approaches described in the following papers.

Sustainability assessments should be objectives-led, rather than merely being a baseline assessment (as is typical of many conventional environmental assessment methodologies). Hacking and Guthrie from the engineering department's Centre for Sustainable Development at Cambridge University, have suggested a way of representing what effective sustainability assessments should achieve. ${ }^{6}$ Thus the three axes of the cube in Fig. 1 show the extent to which any methodology embraces the strategicness of the focus and scope of an assessment, the integratedness of the techniques and themes employed and the comprehensiveness of the coverage achieved. Proponents of sustainable development-directed assessment promote varying degrees of movement along one or more of these axes.

There are a range of specific assessment techniques and decision making methodologies discussed in the following pages. It may be revealing to place each of these within Fig. 1's cube. These include multi-criteria decision analysis (MCDA), cost-benefit analysis (CBA), and life cycle assessment (LCA). Elghali et al. offer a concise description and critique of each of these 


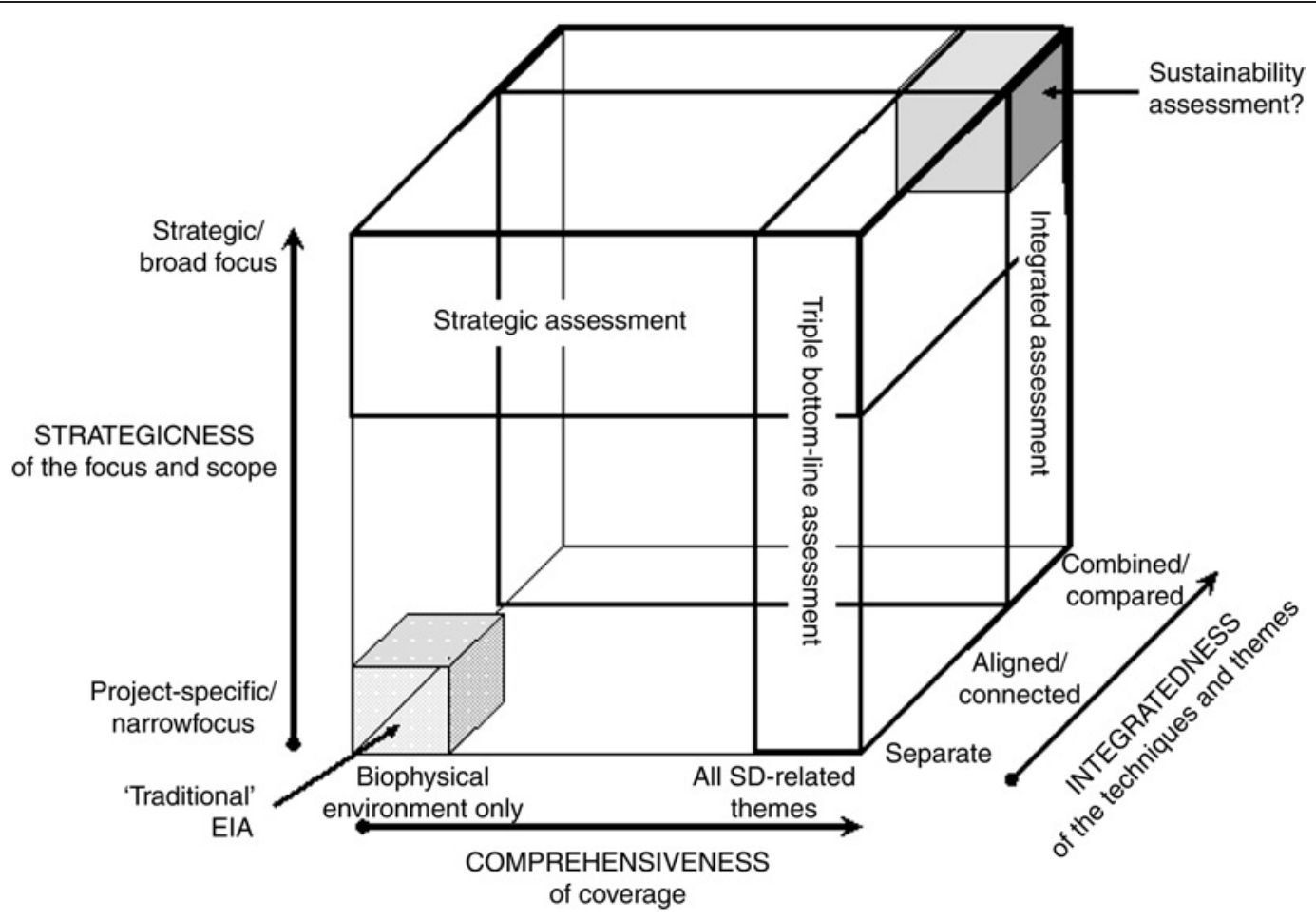

Fig. I. Spectrum of sustainable development-directed features within the assessment process (after Hacking and Guthrie P.6)

alternatives before setting out three case studies to illustrate the use of hybrid approaches which meet the requirements of decision support for complex contexts. Multi-criteria assessment frameworks developed for asset management decision making in the water industry are described by Hurley et al., while Peters et al. tackle the different ways of calculating ecological footprints and apply a revised methodology by increasing geographic resolution and including toxic emissions in a case study concerning the potential upgrade of a sewage treatment plant. Downs' paper provides a critique of traditional 'top down' environmental impact assessment (EIA), in which he argues how a new approach can stimulate a much-needed dialogue between engineers, scientists and policy makers. The two papers by Fenner and Ryce make comparison between the UK Building Research Establishment environmental assessment method (Breeam) and the international leadership in energy and environmental design (Leed), as implemented by the Canada Green Building Council, and indicate some limitations in current practice. These papers are complemented by Campbell Lendrum and Feris' paper on the parallel civil engineering environmental quality assessment and awards scheme (Ceequal), which has been used to benchmark the environmental management on an embankment stabilisation project on the underground Central line in London. The paper by Hunt et al. outlines a variety of sustainability indicators, including Breaam, sustainability checklists and the sustainable project appraisal routine (Spear) method established by Arup. The paper goes on to consider how these operate at a city level, a quarter level or a development site level, through a series of case studies drawn from Birmingham's Eastside. Following a similar theme in relation to property development, the final paper (by Panagiotakopoulos and Jowitt) examines how key performance indicators (KPIs) might evolve from a 'bottom up' input driven process to a 'top down' output driven process, using a systems approach for the design of an output driven approach to assessment which considers appraisal at project level and at process/management level.

Collectively these papers cast considerable light on the art, limitations and applicability of several assessment methodologies, and I hope you find them timely, informative and valuable. The Editorial Panel would welcome discussion on the methods described here and would like to encourage the readership to respond with their views and experiences of the assessment approaches discussed in the following pages.

\section{REFERENCES}

1. JowitT P. Editorial. Proceedings of the Institution of Civil Engineers, Engineering Sustainability, 2007, 160, No. 2, 55-56

2. CIRIA. Sustainable Construction: Company Indicators. Ciria, London, 2001, report C563.

3. Blockley D. and Heslop S. Managing vulnerability and risk for sustainability. Civil Engineering and Environmental Systems, 2001, 18, No. 1, 61-86.

4. Dalman E. Key factors and indicators - how do we use them? Sustainable Building Conference, the Norwegian EcoBuild Programme, Oslo, 2002.

5. MaWhinney M. Sustainable Development: Understanding the Green Debate. Blackwell Science, Oxford, 2002.

6. HACKING T. and Guthrie P. A framework for clarifying the meaning of Triple Bottom-Line, Integrated, and Sustainability Assessment. Environmental Impact Assessment Review, 2007 (doi:10.1016/j.eiar.2007.03.002). 